\title{
Summer of (accounting history) ideas
}

In this issue, Accounting and Cultures offers intriguing contributions from different strand of research, moving from medieval bookkeeping to ruling of minorities within groups of companies (1776-1976) and early examples of social accounting in the American context.

Kuter, Gurskaya and Bagdasaryan have studied the detection of errors in the XIV century, exploring Datini ledger and showing the methods adopted to address mistakes. The paper of Baldissera, that can be located in the field of corporate governance, presents a historical reconstruction of the balance of powers between dominant minorities and disjoint majorities within the groups of companies. The paper of Rusconi belongs to an underexplored area in the accounting history domain: the historical investigation of social accounting. In his work, he explores two U.S. pioneering models of the 1970s showing their importance for affirming the role of accounting research and profession in social/sustainability accounting.

The "Gleanings" present insights on "Quaderno doppio col suo giornale" ("Ledger with its journal") by Domenico Manzoni (1540) and the state-accounting innovation in the Kingdom of Sardinia, offering stimuli for future research.

After wishing you a pleasant reading of this issue, it is a pleasure to report the success of the SISR Summer School of Accounting History held in Pisa (19-22 June), where a group of young scholars interested in exploring the accounting history field attended four-day sessions devoted the main accounting history methodological topics.

A faculty of excellent accounting history scholars have delivered seminars to offer a view on possibilities and criticalities in this field of research. Adriano Prosperi from Scuola Normale Superiore of 
Pisa opened the Summer School with his Lectio magistralis. Marco Guidi (University of Pisa) intervened on methodological issues, while Massimo Sanacore (Pisa State Archive) offered an overview on the Italian archival resources.

The second day was devoted to a) theories - with Christopher Napier (Royal Holloway University of London) on "The New Accounting History and the Roles of Theory", Keith Hoskin (University of Birmingham) on "Michel Foucault and his influence on Accounting History" - , b) accounting history in different academic context (Elena Giovannoni and c) archival sources and practicalities to access them (Roberto Di Pietra, University of Siena). The framing of historical research (Christopher Napier) and the use of Foucault's thought in accounting history (Keith Hoskin) were the topics of the morning of the third day. In the afternoon, Luca Anselmi offered an interesting overview on accounting history education in the Italian context and I had the honour and pleasure to conclude the day, talking about how to publish an accounting history paper. The fourth day session was the part that really made me happy as editor, because I attended a series of projects presentations by young scholars that can be the premise of good papers! Indeed, the Summer School offered the possibility to present projects and ideas to be discussed with the speakers for observations and feedbacks.

It was really a Summer School of ideas and inputs: the 'nurturing path' for young scholars - I proposed in Accounting and Cultures 2/2018 - is becoming a reality and the International Seminar of Accounting History (ISAH) (November 2019) in Siena will be another important moment. 